\title{
JURISPRUDENCIA AMBIENTAL DE LA UNIÓN EUROPEA (PRIMER SEMESTRE 2019)
}

\author{
Rosa GILEs CARNeRo \\ Profesora Titular de Derecho Internacional Público \\ Universidad de Huelva
}


Sumario: 1. Consideraciones introductorias. 2. Recursos por incumplimiento. 3. Recursos de anulación. 4. Recurso de casación. 5. Cuestiones prejudiciales. 5.1. Fomento de la energía procedente de fuentes renovables. 5.2. Evaluación ambiental. 5.3. Conservación de los hábitats naturales y de la fauna y flora silvestres. 5.4. Etiquetado ecológico. 5.5. Residuos.

\section{CONSIDERACIONES INTRODUCTORIAS}

En el período comprendido entre el 1 de octubre de 2018 y el 31 de marzo de 2019, resultan de interés para esta crónica dieciocho sentencias dictadas por el Tribunal de Justicia de la Unión Europea en asuntos relacionados con el derecho ambiental. En primer término, cabe enumerar las sentencias que se produjeron como resultado de procedimientos incoados por la Comisión Europea en el marco del artículo 258 TFUE, en relación con el incumplimiento por parte de Estados miembros de actos legislativos de la Unión Europea que tienen por objeto la protección del medio ambiente. El Tribunal de Justicia emitió siete sentencias en respuesta a recursos por incumplimiento, en las que se abordó la responsabilidad de Alemania, Eslovenia, Irlanda, Italia, Reino Unido, República Checa, y Rumanía. En todos los casos menos en el del recurso contra República Checa, el resultando de las sentencias fue la declaración de incumplimiento.

Asimismo, en el período examinado se dictaron tres sentencias en respuesta a recursos de anulación interpuestos conforme al artículo 263 TFUE, contra actos de las instituciones y órganos de la Unión Europea adoptados en aplicación de normativa con incidencia ambiental. El Tribunal General resolvió dos de estos recursos, denegando uno y aceptando parcialmente otro; mientras que el Tribunal de Justicia se pronunció sobre uno de ellos, desestimando su pertinencia. Asimismo, en el período examinado el Tribunal de Justicia de la Unión Europea emitió una sentencia que resulta de interés en materia ambiental en respuesta a un recurso de casación, interpuesto con arreglo al artículo 56 de su Estatuto. La solución adoptada en este caso fue la desestimación del recurso.

Por último, en el período incluido en la presente crónica se dictaron siete sentencias en respuesta a peticiones de decisión prejudicial remitidas al Tribunal de Justicia por órganos jurisdiccionales nacionales, en relación con la interpretación de distintas disposiciones de contenido ambiental del derecho de 
la Unión Europea. Las cuestiones abordadas en estos pronunciamientos son diversas, de forma que se han incluido en este apartado cinco epígrafes que incluyen las diferentes materias abordadas en las sentencias. En el primer epígrafe aparece una sentencia relativa al fomento de la energía procedente de fuentes renovables; el segundo incluye una sentencia sobre evaluación ambiental; el tercer epígrafe introduce dos sentencias relativas a la conservación de los hábitats naturales y de la fauna y flora silvestres; se añade un cuarto epígrafe en el que se incluye una sentencia sobre etiquetado ecológico; y por último, aparece un apartado relativo a dos sentencias sobre residuos.

\section{RECURSOS POR INCUMPLIMIENTO}

En el periodo comprendido en la presente crónica, se dictaron siete sentencias en respuesta a recursos por incumplimiento. En primer lugar y por orden cronológico, cabe citar la sentencia del Tribunal de Justicia de la Unión Europea (Sala Segunda) de 4 de octubre de 2018, as. C-668/16, Comisión Europea contra República Federal de Alemania, en la que se declaró el incumplimiento por parte del Estado de diversos apartados de la Directiva 2006/40/CE, relativa a las emisiones procedentes de sistemas de aire acondicionado en vehículos de motor, y de la Directiva 2007/46/CE, por la que se crea un marco para la homologación de los vehículos de motor y de los remolques, sistemas, componentes y unidades técnicas independientes destinados a dichos vehículos (Directiva Marco), en su versión modificada por el Reglamento (UE) n. ${ }^{\circ}$ 371/2010 de la Comisión¹.

La Directiva 2006/40/CE estableció que los sistemas de aire acondicionado instalados en todos los tipos de vehículos homologados a partir del 1 de enero de 2011 tendrían que utilizar un refrigerante con un potencial de calentamiento

\footnotetext{
${ }^{1}$ Directiva 2006/40/CE del Parlamento Europeo y del Consejo, de 17 de mayo de 2006, relativa a las emisiones procedentes de sistemas de aire acondicionado en vehículos de motor y por la que se modifica la Directiva 70/156/CEE del Consejo, DO L 161, 14 de junio de 2006, p. 12; y Directiva 2007/46/CE del Parlamento Europeo y del Consejo, de 5 de septiembre de 2007, por la que se crea un marco para la homologación de los vehículos de motor y de los remolques, sistemas, componentes y unidades técnicas independientes destinados a dichos vehículos (Directiva marco), DO, L 263, 5 de septiembre de 2007, p. 1, en su versión modificada por el Reglamento (UE) n. ${ }^{0}$ 371/2010 de la Comisión, de 16 de abril de 2010, DO, L 110, 1 de mayo de 2010, p. 1.
} 
atmosférico que no fuera superior a 150. El Tribunal analizó la actuación de Alemania en relación a diferentes modelos de vehículos, y declaró en este pronunciamiento que había incumplido respecto de algunos de ellos el artículo 5.4 de la Directiva 2006/40/CE, y los artículos 12 y 30 de la Directiva Marco, al no haber adoptado las medidas que garantizaran que se usara un refrigerante con un potencial de calentamiento atmosférico que no sea superior a $150^{2}$. Asimismo, el Tribunal consideró que también se había vulnerado la Directiva 2006/40/CE, y los artículos 5 y 18 de la Directiva Marco al no cumplirse por parte de la empresa las previsiones relativas a la conformidad de la producción y a la entrega de un certificado de conformidad, así como en consecuencia el artículo 46 de la Directiva Marco que establece la obligación de que los Estados establezcan en su derecho nacional "sanciones efectivas, proporcionadas y disuasorias, aplicables en caso de inobservancia por parte de los fabricantes" 3.

En segundo lugar, cabe citar el pronunciamiento incluido en la sentencia del Tribunal de Justicia de la Unión Europea (Sala Sexta) de 18 de octubre de 2018, as. C-669/16, Comisión Europea contra Reino Unido de Gran Bretaña e Irlanda del Norte, en la que se declaró el incumplimiento de la Directiva 92/43/CEE, relativa a la conservación de los hábitats naturales y de la fauna y flora silvestres (Directiva Hábitats) ${ }^{4}$. En este caso, el Tribunal tuvo que pronunciarse sobre una demanda de la Comisión Europea en la que señaló que no se habían designado lugares para la protección de la marsopa común (Phocoena phocoena) en suelo británico, y por lo tanto no se había desarrollado de forma apropiada la Red Natura 2000.

En particular, el Tribunal señaló en su fallo que Reino Unido había vulnerado el artículo 4.1 y los anexos II y III de la Directiva Hábitats "al no haber propuesto y remitido antes del término establecido, de conformidad con esas disposiciones, una lista con indicación de un número suficiente de lugares que alberguen a la marsopa común", a lo que se añadía el incumplimiento del artículo 3.2 "al no haber contribuido, de conformidad con esa disposición, a la creación de la Red

\footnotetext{
2 Véase párrafo 79.

${ }^{3}$ Véanse párrafos 83 y 89.

${ }^{4}$ Directiva 92/43/CEE del Consejo, de 21 de mayo de 1992, relativa a la conservación de los hábitats naturales y de la fauna y flora silvestres, DO, L 206, 22 de julio de 1992, p. 7.
} 
Natura 2000 en función de la representación que tengan en su territorio los hábitats de esa misma especie". En este caso y para declarar el incumplimiento, el Tribunal tuvo en cuenta los datos proporcionados por la Comisión, y el reconocimiento de Reino Unido proporcionado en el escrito de contestación de que no había procedido a designar los lugares de protección de forma suficiente y adecuada $^{5}$.

Un nuevo pronunciamiento fue recogido en la sentencia del Tribunal de Justicia de la Unión Europea (Sala Sexta) de 18 de octubre de 2018, as. C-301/17, Comisión Europea contra Rumanía, en la que se declaró el incumplimiento de la Directiva 1999/31/CE, relativa al vertido de residuos ${ }^{6}$. En este caso, el Tribunal tuvo que valorar la situación de sesenta y ocho vertederos, y pronunciarse sobre si el Estado había cumplido respecto a ellos la normativa en materia de residuos. La decisión, en este caso, fue la declaración del incumplimiento del Estado de los artículos 7.g, 13 y 14.b de la Directiva. En particular, el Tribunal de Justicia declaró que el Estado había incumplido la obligación de tomar todas las medidas necesarias para proceder al cierre de los vertederos que no habían obtenido las oportunas autorizaciones? ${ }^{7}$.

Una nueva condena a un Estado miembro se incluyó en la sentencia del Tribunal de Justicia de la Unión Europea (Sala Sexta) de 28 de noviembre de 2018, as. C-506/17, Comisión Europea contra República de Eslovenia, en la que se declaró el incumplimiento de la Directiva 1999/31/CE, relativa al vertido de residuos. En su pronunciamiento, el Tribunal consideró que el Estado había vulnerado diversos artículos de la Directiva, al no haber tomado las medidas necesarias para hacer cumplir sus previsiones en relación a determinados vertederos situados en suelo esloveno. En la mayor parte de los vertederos analizados por el Tribunal, se apreció que no habían obtenido autorización para realizar su actividad conforme al artículo 8 de la Directiva, de forma que al no clausurarlos el Estado había incumplido sus obligaciones conforme a los artículos 7.g) y 13 de la Directiva relativos al procedimiento de cierre y

\footnotetext{
${ }^{5}$ Véanse párrafos 65 y 66.

${ }^{6}$ Directiva 1999/31/CE del Consejo, de 26 de abril de 1999, relativa al vertido de residuos, DO, L 182, 16 de julio de 1999, p. 1.

${ }^{7}$ Véase párrafo 47.
} 
mantenimiento posterior ${ }^{8}$. Sólo en un caso, el Tribunal apreció que el incumplimiento del Estado provenía únicamente del incumplimiento de lo previsto en el punto 1 del Anexo I de la Directiva relativo a la ubicación ${ }^{9}$. Asimismo, el Tribunal consideró que Eslovenia había incumplido los apartados $b$ y $c$ del artículo 14 de la Directiva al no haber desarrollado un plan de acondicionamiento adecuado y haber adoptado, en consecuencia, una decisión definitiva que permitiera un desarrollo de la actividad conforme a sus indicaciones ${ }^{10}$.

El quinto pronunciamiento a incluir en esta crónica se refiere a la sentencia del Tribunal de Justicia de la Unión Europea (Sala Primera) de 14 de marzo de 2019, as. C-399/17, Comisión Europea contra República Checa, relativa al cumplimiento del Reglamento (CE) n. ${ }^{\circ}$ 1013/2006, relativo a los traslados de residuos $^{11}$. En este caso, el Tribunal de Justicia no estimó que se hubiese producido el incumplimiento del Reglamento al negarse la República Checa a garantizar el retorno de la mezcla TPS-NOLO o Geobal, que había sido previamente trasladada desde este Estado a Polonia. El Tribunal analizó los datos aportados por la Comisión y declaró que de estos no de deducía que "la Comisión haya aportado una prueba suficiente en Derecho del carácter de residuo", en consecuencia declaró que "no ha demostrado que el traslado de la mezcla de la República Checa a Polonia entre finales de 2010 y principios de 2011 haya constituido, en la fecha en que fue realizado, un traslado de residuos, en el sentido del Reglamento n. ${ }^{0} 1013 / 2006 "{ }^{12}$. En relación con este pronunciamiento cabe destacar que el Tribunal se mostró tajante ante la pretensión de la Comisión de que no fuera necesaria su actuación para demostrar la cualidad de residuo, al señalar que "la Comisión incurrió en error al sostener que no le correspondía aportar la carga de la prueba de que la mezcla

\footnotetext{
${ }^{8}$ Véase párrafo 67.

${ }^{9}$ Véase párrafo 62.

${ }^{10}$ Véanse párrafos 61 y 66.

${ }^{11}$ Reglamento (CE) n. ${ }^{\circ}$ 1013/2006 del Parlamento Europeo y del Consejo, de 14 de junio de 2006, relativo a los traslados de residuos, DO, L 190, 12 de julio de 2006, p. 1.

${ }^{12}$ Véase párrafo 78.
} 
en cuestión debe calificarse como "residuo" a efectos del presente procedimiento por incumplimiento"13.

En sexto lugar, cabe señalar la sentencia del Tribunal de Justicia de la Unión Europea (Sala Décima) de 28 de marzo de 2019, as. C-427/17, Comisión Europea contra Irlanda, en la que se declaró el incumplimiento de la Directiva 91/271/EEC, sobre el tratamiento de las aguas residuales urbanas, en su versión modificada por el Reglamento (CE) n. ${ }^{0}$ 1137/2008 ${ }^{14}$. El Tribunal analizó la situación del tratamiento de las aguas residuales en diferentes aglomeraciones urbanas, y consideró que se habían vulnerado diversas obligaciones incluidas en la Directiva 91/271/EEC ${ }^{15}$.

En particular, en el fallo de la sentencia se señaló que se habían vulnerado los apartados 1 y 2 del artículo 3 y la sección A del Anexo I de esta norma, al no haber asegurado el Estado en algunas aglomeraciones que las aguas recogidas en sistemas combinados de aguas residuales urbanas y aguas pluviales, se retuvieran y condujeran conforme a los requisitos exigidos. También los párrafos 1 y 3 del artículo 4, en conjunción con el artículo 10 y la sección B del Anexo I de la Directiva 91/271/EEC, fueron considerados vulnerados en relación con algunas de las aglomeraciones urbanas examinadas, al no haberse aplicado un tratamiento secundario o equivalente. Asimismo, el Tribunal apreció la vulneración de los párrafos 2 y 3 del artículo 5, en conjunción con el artículo 19 y la sección B del Anexo I al no haber asegurado en Estado que las aguas residuales urbanas entraran en sistemas colectores. Por último, el Tribunal declaró la vulneración de artículo 12 al considerar que no se había asegurado que la eliminación de las aguas residuales de las depuradoras se sujetara a regulaciones previas y/o a autorización específica.

El último caso a reseñar en la presente crónica se incluyó en la sentencia del Tribunal de Justicia de la Unión Europea (Sala Quinta) de 21 de marzo de 2019,

\footnotetext{
13 Véase párrafo 54.

${ }^{14}$ Directiva 91/271/EEC del Consejo, de 21 de mayo de 1991, sobre el tratamiento de las aguas residuales urbanas, DO, L 135, de 30 de mayo de 1991, p. 40; y Reglamento (CE) n. ${ }^{\circ}$ 1137/2008 del Parlamento Europeo y del Consejo, de 22 de octubre 2008, por el que se adaptan a la Decisión 1999/468/CE del Consejo determinados actos sujetos al procedimiento establecido en el artículo 251 del Tratado, en lo que se refiere al procedimiento de reglamentación con control, DO; L 311, 21 de noviembre de 2008, p. 1.

15 Véase párrafo 231.
} 
as. C-498/17, Comisión Europea contra República Italiana, en la que se declaró el incumplimiento de la Directiva 1999/31/CE, relativa al vertido de residuos. El Tribunal procedió a analizar la situación de diferentes vertederos situados en suelo italiano, y como consecuencia de este análisis, dictaminó que el Estado había incumplido el artículo 14.b) y c) al no haber adoptado todas medidas necesarias para cerrar lo antes posible aquellos que "no habían obtenido, de conformidad con el artículo 8 de dicha Directiva, autorización para continuar sus actividades o al no haber adoptado las medidas necesarias para adaptar a la Directiva los vertederos que habían obtenido autorización para continuar su funcionamiento"16. El Tribunal recordó en su argumentación que el artículo 14 de la Directiva 1999/31/CE establece un régimen transitorio de excepción, que permitía ajustar esos vertederos a los nuevos requisitos medioambientales requeridos. De los datos proporcionados por la Comisión cabía deducir que en los vertederos analizados no se había procedido a este procedimiento de adaptación, por lo que se produciría la declaración de incumplimiento ${ }^{17}$.

\section{RECURSOS DE ANULACIÓN}

En el período revisado en esta crónica, resultan relevantes tres sentencias emitidas en respuesta a recursos de anulación presentados contra actos de la Unión Europea con contenido ambiental. En primer término, en un orden cronológico, cabe señalar la sentencia del Tribunal General (Sala Segunda) de 24 de octubre de 2018, as. T-400/17, Deza, a.s. contra Comisión Europea, mediante la que se resolvió un recurso en relación a la anulación del Reglamento (UE) 2017/776 de la Comisión, sobre clasificación, etiquetado y envasado de sustancias y mezclas, en lo que se refiere a la clasificación de la antraquinona como una sustancia con potencial cancerígeno para los seres humanos ${ }^{18}$. En

\footnotetext{
16 Véase párrafo 37.

17 Véase párrafo 26.

${ }^{18}$ Reglamento (UE) 2018/1480 de la Comisión, de 4 de octubre de 2018, por el que se modifica, a efectos de su adaptación al progreso técnico y científico, el Reglamento (CE) n. ${ }^{\circ}$ 1272/2008 del Parlamento Europeo y del Consejo, sobre clasificación, etiquetado y envasado de sustancias y mezclas, y se corrige el Reglamento (UE) 2017/776 de la Comisión, DO, L 116, 5 de octubre de 2018, p. 1.
} 
este caso el Tribunal no aceptó el recurso planteado, y para ello desarrolló un análisis de la norma mediante el que fundamentó su conclusión de que no se había incurrido en ilegalidades ni errores ${ }^{19}$. Asimismo, introdujo la reflexión sobre la aplicación a este caso del principio de seguridad jurídica y el derecho de propiedad, y consideró que no se habían aportado argumentos para apoyar que habían sido conculcados por el Reglamento (UE) 2017/776 20 .

En segundo lugar, cabe citar la sentencia del Tribunal General (Sala Novena ampliada) de 13 de diciembre de 2018, as. T-339/16, T-352/16 y T-391/16, Ville de Paris (Francia), Ville de Bruxelles (Bélgica) y Ayuntamiento de Madrid contra Comisión Europea, en la que se estimó parcialmente el recurso planteado contra el Reglamento (UE) 2016/646, en lo que concierne a las emisiones procedentes de turismos y vehículos comerciales ligeros (Euro 6) ${ }^{21}$. Los demandantes solicitaron la nulidad del Reglamento al considerar que la Comisión Europea no podía adoptar los valores no sobrepasables (NTE) de las emisiones de óxidos de nitrógeno que incluye, y que son superiores a los límites de estas emisiones fijados para la norma Euro 6. Para emitir su pronunciamiento, el Tribunal analizó de forma pormenorizada los diferentes elementos que se incluyen en el Reglamento, y aceptó los argumentos de los demandantes para anular, en particular, "el punto 2 del anexo II del Reglamento impugnado en la medida en que fija, en los puntos 2.1.1 y 2.1.2 del anexo III A del Reglamento n. ${ }^{0}$ 692/2008, el valor del factor de conformidad CFpollutant definitivo y el valor del factor de conformidad CFpollutant temporal con respecto a la masa de los óxidos de nitrógeno" 22.

En este pronunciamiento, el Tribunal desarrolló algunas reflexiones particulares sobre el alcance y los efectos en el tiempo de la anulación declarada. Respecto al alcance de la anulación, se recordó en el pronunciamiento que "para adecuarse a una sentencia de anulación y darle plena ejecución, la institución

\footnotetext{
19 Véase párrafo 99.

${ }^{20}$ Véanse párrafos 99 y 109.

${ }^{21}$ Reglamento (UE) 2016/646 de la Comisión, de 20 de abril de 2016, por el que se modifica el Reglamento (CE) n. ${ }^{\circ}$ 692/2008 en lo que concierne a las emisiones procedentes de turismos y vehículos comerciales ligeros (Euro 6), DO, L 109, 26 de abril de 2016, p. 1.

22 Véase párrafo 158.
} 
autora de la disposición anulada debe eliminarla de los actos subsiguientes de los que sea autora en los que se haya incluido esta disposición y excluirla de sus actos futuros, teniendo en cuenta no solo el fallo de la sentencia, sino también los fundamentos que han llevado a este y que constituyen su sustento necesario"23. Respecto a los efectos en el tiempo de la anulación, el Tribunal consideró que se debían modular para no generar perjuicios a intereses económicos del sector del automóvil y de los consumidores, así como de la protección ambiental y de la salud. En consecuencia, se declaró que "los efectos de la disposición anulada sean definitivos para el "pasado", en el sentido que se ha precisado en el anterior apartado, y que se mantengan para el futuro durante un período razonable que permita modificar la normativa en la materia, el cual no podrá exceder de doce meses a partir de que esta sentencia surta efecto"24.

En tercer y último lugar, cabe señalar la sentencia del Tribunal de Justicia (Sala Sexta) de 13 de marzo de 2019, as. C-128/17, República de Polonia contra Parlamento Europeo y Consejo de la Unión Europeo, en la que se desestimó el recurso interpuesto por el Estado en el que se pedía la anulación de la Directiva (UE) 2016/2284, relativa a la reducción de las emisiones nacionales de determinados contaminantes atmosférico, y con carácter subsidiario, que se anulase en lo que respecta a los compromisos nacionales de reducción de estas emisiones hasta $2030^{25}$. En su recurso, Polonia alegó diferentes motivos para fundamentar la nulidad de la Directiva, todos los cuales fueron desestimados por el Tribunal. En particular, mientras que Polonia alegó que el Parlamento y el Consejo habían incumplido la obligación de realizar una evaluación de impacto adecuada de la Directiva antes de su adopción, en la sentencia se señaló "que, durante el procedimiento legislativo, el Parlamento y el Consejo tuvieron en cuenta los datos científicos y la información disponibles para ejercer efectivamente su facultad de apreciación" ${ }^{26}$. Asimismo, Polonia alegó que el

\footnotetext{
${ }^{23}$ Véase párrafo 159.

${ }^{24}$ Véase párrafo 163.

${ }^{25}$ Directiva (UE) 2016/2284 del Parlamento Europeo y del Consejo, de 14 de diciembre de 2016, relativa a la reducción de las emisiones nacionales de determinados contaminantes atmosféricos, por la que se modifica la Directiva 2003/35/CE y se deroga la Directiva 2001/81/CE, DO, L 344, 17 de diciembre de 2016, p. 1.

${ }^{26}$ Véanse párrafos 21 y 45.
} 
Parlamento y el Consejo no cumplieron los principios de cooperación leal, de transparencia y de apertura, y la obligación de motivar los actos jurídicos, y también se desestimaron estas alegaciones ${ }^{27}$. Por último, el Estado alegó que la Directiva podía suponerle especiales cargas socioeconómicas, por lo que vulneraría el principio de proporcionalidad y el de igualdad, pero también estas alegaciones fueron rechazadas por el Tribunal ${ }^{28}$.

\section{RECURSOS DE CASACIÓN}

En el periodo incluido en la presente crónica, el Tribunal de Justicia de la Unión Europea emitió una sentencia en respuesta a un recurso de casación contra un pronunciamiento del Tribunal General. La sentencia del Tribunal de Justicia de la Unión Europea (Sala Primera) de 23 de enero de 2019, as. C-419/17 P, Deza a.s. contra Agencia Europea de Sustancias y Mezclas Químicas (ECHA), desestimó la petición de anulación de la sentencia del Tribunal General de la Unión Europea de 11 de mayo de 2017, as. T-115/15, Deza contra ECHA. En aquella primera sentencia, el Tribunal General había desestimado el recurso que solicitaba la anulación de la Decisión ED/108/2014 del director ejecutivo de la ECHA, de 12 de diciembre de 2014, en la que se actualizaba y se completaba la entrada de la sustancia química ftalato de bis (2-etilhexilo) (CE n. ${ }^{\circ}$ 204-211-0, CAS n. ${ }^{\circ}$ 117-81-7) en la lista de posibles sustancias que podrían ser incluidas en el anexo XIV del Reglamento n. ${ }^{0}$ 1907/2006 relativo al registro, la evaluación, la autorización y la restricción de las sustancias y mezclas químicas (REACH), en su versión modificada por el Reglamento n. ${ }^{\circ}$ 895/2014 ${ }^{29}$. Después de examinar

\footnotetext{
${ }^{27}$ Véanse párrafos 48 y 82.

${ }^{28}$ Véanse párrafos 83, 118, 119 y 147.

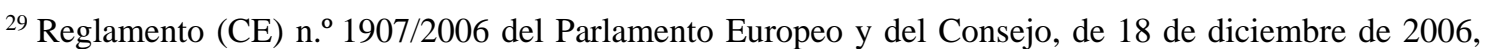
relativo al registro, la evaluación, la autorización y la restricción de las sustancias y mezclas químicas (REACH), por el que se crea la Agencia Europea de Sustancias y Mezclas Químicas, se modifica la Directiva 1999/45/CE y se derogan el Reglamento (CEE) n. ${ }^{\circ}$ 793/93 del Consejo y el Reglamento (CE) n. ${ }^{\circ}$ 1488/94 de la Comisión así como la Directiva 76/769/CEE del Consejo y las Directivas 91/155/CEE, 93/67/CEE, 93/105/CE y 2000/21/CE de la Comisión, DO, L 396, 30 de diciembre de 2006, p. 1; y Reglamento (CE) n. ${ }^{\circ}$ 895/2014 de la Comisión, de 14 de agosto de 2014, por el que se modifica el anexo XIV del Reglamento (CE) n 1907/2006 del Parlamento Europeo y del Consejo, relativo al registro, la evaluación, la autorización y la restricción de las sustancias y mezclas químicas (REACH), DO, L 244, 19 de agosto de 2014, p. 6.
} 
el caso, el Tribunal de Justicia no observó que se hubiese dado ningún error en la sentencia cuestionada, por lo que no aceptó las diferentes alegaciones formuladas por la parte demandante.

En particular, Deza alegó que se había incurrido en un error de derecho en la primera sentencia al declarar que la ECHA era competente para adoptar la Decisión controvertida y que se había adoptado siguiendo el procedimiento debido; a lo que se sumó la alegación de que era contraria al principio de seguridad jurídica, debido a que había dado lugar a "una situación jurídica confusa, imprecisa e imprevisible para la recurrente" ${ }^{30}$. Asimismo, Deza también alegó que "el Tribunal General examinó la Decisión controvertida sin cumplir las exigencias relativas al alcance del control jurisdiccional de las decisiones de las instituciones y órganos de la Unión y que desnaturalizó las pruebas que se le presentaron"31. El Tribunal rechazó estas alegaciones.

La parte demandante añadiría una última alegación de vulneración de derechos fundamentales recogidos en el Convenio Europeo para la Protección de los Derechos Humanos y de las Libertades Fundamentales, y en la Carta de los Derechos Fundamentales de la Unión Europea ${ }^{32}$. Respecto a esta última pretensión, el Tribunal de Justicia consideró que carecía "manifiestamente de fundamentación y precisión, ya que solo hace una formulación abstracta de normas de Derecho que el Tribunal General supuestamente vulneró y no va acompañado de ninguna argumentación" 33.

\section{CUESTIONES PREJUDICIALES}

\subsection{Fomento de la energía procedente de fuentes renovables}

En el periodo comprendido en la presente crónica, el Tribunal de Justicia resolvió una cuestión prejudicial planteada en relación al régimen para el fomento de la energía procedente de fuentes renovables. La Sentencia del Tribunal de Justicia

\footnotetext{
${ }^{30}$ Véanse párrafos 20 y ss; y 63 y ss.

${ }^{31}$ Véanse párrafos 76 y ss.

32 Véase párrafo 90.

33 Véase párrafo 92.
} 
(Sala Segunda) de 24 de octubre de 2018, as. C-242/17, Legatoria Editoriale Giovanni Olivotto (L.E.G.O.) SpA contra Gestore dei servizi energetici (GSE) SpA y otros, resolvió la cuestión prejudicial planteada por el Consejo de Estado de Italia sobre la interpretación de la Directiva 2009/28/CE, relativa al fomento del uso de energía procedente de fuentes renovables, en relación con la Decisión de Ejecución 2011/438/UE de la Comisión, sobre el sistema de verificación de los criterios de sostenibilidad que incluye la Directiva ${ }^{34}$. En particular, el órgano jurisdiccional preguntó sobre la interpretación del 18.7 de la Directiva, que prevé que sean suficientes los datos presentados por un operador económico respecto al cumplimiento de las condiciones de sostenibilidad del artículo 17 de la misma norma, cuando lo haya hecho conforme a una Decisión de Ejecución, como es la 2011/438/UE, y su compatibilidad con una normativa nacional que requería obligaciones diferentes y más amplias que las incluidas en la Decisión de Ejecución 2011/438/UE ${ }^{35}$. Para el caso de que se declarase la compatibilidad de las previsiones nacionales con el Derecho de la Unión Europea, el órgano jurisdiccional nacional añadió una segunda pregunta en relación a si quedaban vinculados por la normativa europea "los operadores económicos que intervienen en la cadena de suministro del producto, incluso cuando se trate de operadores que desempeñan actividades de simple intermediación en las que no disponen materialmente del producto" ${ }^{36}$.

En relación a la primera pregunta planteada, el Tribunal de Justicia recordó, de forma preliminar, que los criterios de sostenibilidad incluidos en el artículo 17 de la Directiva 2009/28 se refieren a los biocarburantes y los biolíquidos que puedan calificarse como fuente de energía renovable ${ }^{37}$. En consecuencia, el Tribunal declaró que el artículo 18.7 de la Directiva 2009/28, en relación a la Decisión de

\footnotetext{
${ }^{34}$ Directiva 2009/28/CE, del Parlamento Europeo y del Consejo, de 23 de abril de 2009, relativa al fomento del uso de energía procedente de fuentes renovables y por la que se modifican y se derogan las Directivas 2001/77/CE y 2003/30/CE, DO, L 140, 5 de junio de 2009, p. 16; y Decisión de Ejecución 2011/438/UE de la Comisión, de 19 de julio de 2011, sobre el reconocimiento del régimen «International Sustainability and Carbon Certification» para demostrar el cumplimiento de los criterios de sostenibilidad de conformidad con las Directivas 2009/28/CE y 2009/30/CE del Parlamento Europeo y del Consejo, DO, L 190, 21 de junio de 2011.

${ }^{35}$ Véase párrafo 25.

${ }^{36}$ Ibidem.

${ }^{37}$ Véase párrafo 27.
} 
Ejecución 2011/438/UE "no se opone a una normativa nacional, como la controvertida en el litigio principal, que impone a los agentes económicos requisitos específicos, diferentes y más amplios, para la certificación de la sostenibilidad de los biolíquidos que los establecidos en un régimen voluntario de certificación de la sostenibilidad, como el sistema ISCC, reconocido por dicha Decisión de Ejecución, adoptada por la Comisión de conformidad con el artículo 18, apartado 4, de la citada Directiva, por cuanto dicho sistema fue aprobado únicamente para los biocarburantes y dichos requisitos solo se refieren a los biolíquidos"38.

Una vez contestada la primera pregunta en el sentido de la compatibilidad de la norma nacional con el Derecho de la Unión Europea, procedía la valoración de la segunda de las cuestiones planteadas. Para ello, el Tribunal de Justicia consideró que procedía evaluar también si el artículo 34 del Tratado de Funcionamiento de la Unión Europea, relativo a la libre circulación de mercancías, se opone a una normativa nacional como la controvertida en el litigio principal $^{39}$. El Tribunal señaló que la normativa nacional evaluada constituía una medida de efecto equivalente a las restricciones cuantitativas a las importaciones, que en principio sería incompatible con el artículo 34 TFUE, a menos que concurriera una justificación como ocurre en este caso, al contribuir la medida nacional a la protección de la salud y de la vida de las personas y los animales, así como a la preservación de los vegetales ${ }^{40}$. Como consecuencia de la argumentación desarrollada, en la sentencia se respondió a la segunda cuestión señalando "que el Derecho de la Unión, en particular el artículo 34 TFUE y el artículo 18, apartados 1 y 3, de la Directiva 2009/28, debe interpretarse en el sentido de que no se opone a que una normativa nacional, como la controvertida en el litigio principal, imponga un sistema nacional de verificación de la sostenibilidad de los biolíquidos que establece que todos los agentes económicos que intervienen en la cadena de suministro del producto, aun cuando se trate de intermediarios que no dispongan físicamente de los

\footnotetext{
38 Véase párrafo 41.

39 Véase párrafo 44.

${ }^{40}$ Véanse párrafos 62 y 70.
} 
biolíquidos, están sujetos a determinadas obligaciones de certificación, comunicación e información resultantes de dicho sistema"41.

\subsection{Evaluación ambiental}

En el período analizado en esta crónica, el Tribunal de Justicia emitió una sentencia que respondía a una cuestión prejudicial relativa a la interpretación de normativa europea sobre evaluación ambiental. La sentencia del Tribunal de Justicia de la Unión Europea (Sala Primera) de 17 de octubre de 2018, as. C167/17, Volkmar Klohn contra An Bord Pleanála, resolvió una cuestión prejudicial planteada por el Tribunal Supremo de Irlanda que tuvo como objeto la interpretación de la Directiva 85/337/CEE, relativa a la evaluación de las repercusiones de determinados proyectos públicos y privados sobre el medio ambiente, en su versión modificada por la Directiva 2003/35/CE ${ }^{42}$. En particular, el órgano jurisdiccional nacional presentó la cuestión sobre la interpretación del artículo 10 bis de esta disposición, que establece la obligación de que los procedimientos de recurso no sean excesivamente onerosos, en relación a la imposición de costas de un procedimiento judicial entablado contra el permiso de construcción en el Condado de Sligo de un centro de inspección de animales muertos en todo el territorio irlandés ${ }^{43}$.

El Tribunal de Justicia precisó que, ante la situación de no trasposición del artículo 10 bis de la Directiva 85/337/CEE en Irlanda, para responder a las cuestiones planteadas procedía, en primer término, analizar si el requerimiento de este artículo para que determinados procedimientos judiciales en materia de medio ambiente no sean excesivamente onerosos, tiene efecto directo o si únicamente supone el requerimiento para el juez nacional de que interprete el Derecho interno de forma que se intente el logro de este objetivo ${ }^{44}$. El Tribunal

\footnotetext{
${ }^{41}$ Véanse párrafos 72.

${ }^{42}$ Directiva 85/337/CEE del Consejo, de 27 de junio de 1985, relativa a la evaluación de las repercusiones de determinados proyectos públicos y privados sobre el medio ambiente, DO, L 175, 5 de julio de 1985, p. 40; y Directiva 2003/35/CE del Parlamento Europeo y del Consejo, de 26 de mayo de 2003, DO, L 156, 25 de junio de 2003, p. 17.

${ }^{43}$ Véase párrafo 24.

${ }^{44}$ Véase párrafo 26.
} 
no reconoció el efecto directo del artículo 10 bis, aunque precisó que en una situación como la controvertida, en la que no se ha realizado la transposición, los órganos jurisdiccionales nacionales deben "en la medida de lo posible, interpretar el Derecho interno, a partir de la expiración del plazo previsto para la transposición de dicho artículo, de tal manera que no se impida a los particulares interponer un recurso judicial comprendido en el ámbito de aplicación del mismo artículo, o continuar con dicho recurso, debido a la carga económica que de ello podría resultar"45.

Resuelto el primer planteamiento en los términos señalados, el Tribunal incluyó en su fallo dos declaraciones mediante las que se precisó sus consecuencias respecto al momento en el que se habían fijado las costas, y si éstas tuvieran efecto de cosa juzgada. En este sentido, se precisó que el artículo 10 bis “debe interpretarse en el sentido de que la obligación de interpretación conforme es vinculante para los órganos jurisdiccionales de un Estado miembro al pronunciarse sobre la imposición de costas en los procedimiento judiciales que estaban pendientes en la fecha de expiración del plazo de transposición de la exigencia de que determinados procedimientos judiciales en materia de medio ambiente no sean excesivamente onerosos, prevista en dicho artículo 10 bis, párrafo quinto, con independencia de la fecha en que se devengaran tales costas a lo largo del procedimiento en cuestión". Asimismo, en un último apartado se declaró que este precepto "debe interpretarse en el sentido de que, en un procedimiento como el del litigio principal, la obligación de interpretación conforme corresponde al juez nacional que debe pronunciarse sobre el importe de las costas, en la medida en que no se oponga a ello la fuerza de cosa juzgada de la resolución sobre imposición de costas que ha adquirido firmeza, extremo que corresponde verificar al órgano jurisdiccional remitente".

\subsection{Conservación de los hábitats naturales y de la fauna y flora silvestres}

En el período temporal fijado por esta crónica, el Tribunal de Justicia de la Unión Europea resolvió dos cuestiones prejudiciales relativas a la interpretación de

${ }^{45}$ Véase párrafo 36. 
normativa europea en materia de conservación de los hábitats naturales, y de la fauna y flora silvestres. Mediante la sentencia del Tribunal de Justicia de la Unión Europea (Sala Segunda) de 7 de noviembre de 2018, as. C-293/17 y C-294/17, Coöperatie Mobilisation for the Environment UA y Vereniging Leefmilieu contra College van gedeputeerde staten van Limburg, y College van gedeputeerde staten van Gelderland; y Stichting Werkgroep Behoud de Peel contra College van gedeputeerde staten van Noord-Brabant, se resolvieron diferentes preguntas planteadas por el Consejo de Estado de Países Bajos, sobre la interpretación de la Directiva 92/43/CEE, relativa a la conservación de los hábitats naturales y de la fauna y flora silvestres (Directiva Hábitats) ${ }^{46}$. En particular, en esta cuestión prejudicial se requirió al Tribunal de Justicia que desarrollase la interpretación del artículo 6 de la Directiva Hábitats, relativo a la conservación de las zonas especiales de conservación, en relación a la normativa sobre autorización para actividades agrícolas que generan deposiciones de nitrógeno en lugares de la red Natura 2000.

Esta sentencia se originó por acumulación de dos casos en los que se plantearon preguntas comunes y relacionadas, las cuales llevarían al Tribunal de Justicia a desarrollar el análisis de diversos puntos de la normativa nacional de autorización de actividades agrícolas que generan deposiciones de nitrógeno en lugares de la red Natura $2000^{47}$. Este examen llevó al Tribunal de Justicia a precisar en su fallo la interpretación del artículo 6 de la Directiva Hábitats, y su compatibilidad con la normativa nacional controvertida. En primer término, precisó que "las actividades de pastoreo de ganado y de vertido de residuos líquidos en el suelo cerca de zonas Natura 2000 pueden calificarse de "proyecto" en el sentido de dicha disposición". Se precisa, asimismo, que una actividad recurrente, como el vertido de residuos líquidos en el suelo, puede considerarse un único y mismo proyecto, y se le debe aplicar el artículo 6 en su ejecución, aunque haya sido autorizado previamente a que le resultase de aplicación.

A lo anterior se añade que el artículo 6 no se opone a una normativa nacional que "permite a las autoridades competentes autorizar proyectos basándose en

\footnotetext{
${ }^{46}$ Directiva 92/43/CEE del Consejo, de 21 de mayo de 1992, relativa a la conservación de los hábitats naturales y de la fauna y flora silvestres, DO, L 206, 22 de julio de 1992, p. 7.

${ }^{47}$ Véase párrafo 49.
} 
una "adecuada evaluación" en el sentido de dicha disposición, realizada con anterioridad y en la que se ha declarado compatible con los objetivos de protección de dicha normativa determinada cantidad global de deposiciones de nitrógeno"; tampoco a aquella que "exime a determinados proyectos que no alcanzan un determinado umbral o que no superan cierto límite máximo en términos de deposiciones de nitrógeno de la necesidad de obtener una autorización individual si el órgano jurisdiccional nacional tiene la certeza de que la "adecuada evaluación" en el sentido de dicha disposición, realizada anteriormente, cumple el requisito de que no existe duda científica razonable de que esos planes o proyectos no tienen efectos perjudiciales para la integridad de los lugares en cuestión"; ni a la "que permite que cierta categoría de proyectos [...] se ejecute sin estar sometida a la obligación de autorización y, por tanto, a una adecuada evaluación individualizada de sus repercusiones en los lugares en cuestión, a menos que circunstancias objetivas permitan excluir con certeza cualquier posibilidad de que dichos proyectos, individualmente o junto con otros proyectos, puedan afectar de forma apreciable a esos lugares, extremo que corresponde verificar al órgano jurisdiccional remitente".

Asimismo, el Tribunal declaró que la adecuada evaluación a la que se refiere el artículo 6 "no puede tener en cuenta la existencia de "medidas de conservación" en el sentido del apartado 1 de dicho artículo, de "medidas de prevención" en el sentido del apartado 2 del citado artículo, de medidas adoptadas específicamente para un programa como el controvertido en el litigio principal ni tampoco de medidas denominadas "autónomas", al ser esas medidas ajenas a dicho programa, si los beneficios previstos de las citadas medidas no son ciertos en el momento de esa evaluación". Por último, el Tribunal declaró que debe considerarse que se produce el cumplimiento de los requerimientos del artículo 6 si se produce una normativa nacional como la evaluada, que incluye previsiones de supervisión, control, y sanciones que pueden incluir el cierre.

En segundo lugar, la sentencia del Tribunal de Justicia de la Unión Europea (Sala Segunda) de 7 de noviembre de 2018, as. C-461/17, Brian Holohan y otros contra An Bord Pleanála, resolvió una cuestión prejudicial planteada por el Tribunal Superior de Irlanda, y que tuvo como objeto la interpretación de la Directiva Hábitats y la Directiva 2011/92/UE, relativa a la evaluación de las repercusiones 
de determinados proyectos públicos y privados sobre el medio ambiente ${ }^{48}$. En particular, el órgano jurisdiccional nacional planteó diversas preguntas en relación con la compatibilidad de esta normativa europea, y la autorización de un proyecto de extensión del periférico norte de la ciudad de Kilkenny.

En este caso, el Tribunal tuvo de nuevo la oportunidad de interpretar el artículo 6 de la Directiva Hábitats, e incluyó en su fallo diversas aseveraciones en relación al caso controvertido. En primer lugar, se refirió a la categoría de "adecuada evaluación" incluida en este precepto, y señaló que "ha de, por una parte, contabilizar todos los tipos de hábitats y especies con respecto a los cuales un lugar está protegido y, por otra, identificar y examinar tanto las repercusiones del proyecto propuesto en las especies presentes en ese lugar, y con respecto a las cuales este no ha sido clasificado, como las repercusiones en los tipos de hábitats y especies situados fuera de los límites de dicho lugar, siempre que tales repercusiones puedan afectar a los objetivos de conservación del lugar". A esto añadió que el mandato de este precepto "solo permite a la autoridad competente autorizar un plan o proyecto que deje al promotor libre para determinar posteriormente algunos parámetros relativos a la fase de construcción, [...] si la autorización fija requisitos suficientemente estrictos que garanticen que estos parámetros no causarán perjuicio a la integridad del lugar"; y que "cuando la autoridad competente rechaza las conclusiones de un dictamen científico que propugna la obtención de información adicional, la "adecuada evaluación" debe comportar una motivación explícita y detallada, que permita disipar cualquier duda científica razonable acerca de los efectos de las obras previstas en el lugar concernido".

El Tribunal también fue requerido a la interpretación del artículo 5 y el Anexo IV de la Directiva 2011/92/UE, en relación a la autorización controvertida. A este respecto, en el fallo de la sentencia, se declaró que las previsiones europeas "deben interpretarse en el sentido de que imponen al promotor la obligación de aportar información que analice expresamente las repercusiones significativas de su proyecto en todas las especies indicadas en la declaración presentada en

\footnotetext{
${ }^{48}$ Directiva 2011/92/UE del Parlamento Europeo y del Consejo, de 13 de diciembre de 2011, relativa a la evaluación de las repercusiones de determinados proyectos públicos y privados sobre el medio ambiente, DO, L 26, 28 de enero de 2012, p. 1.
} 
aplicación de estas disposiciones". En último término se añadió que "el promotor ha de aportar información relativa a las repercusiones medioambientales tanto de la solución adoptada como de cada una de las principales alternativas estudiadas por él, así como las razones de su elección, a la luz, al menos, de sus repercusiones en el medio ambiente, aun en caso de rechazo en una fase temprana de tal alternativa".

\subsection{Etiquetado ecológico.}

En este apartado se incluye una sentencia relativa a etiquetado ecológico, y que vino referida a un caso principal en el que se pretendía prohibir a la empresa Tendre France la publicidad y la comercialización de productos de carne de vacuno con la certificación halal y la mención de agricultura ecológica. La sentencia del Tribunal de Justicia de la Unión Europea (Gran Sala) de 26 de febrero de 2019, as. C-497/17, Fuvre d'assistance aux bêtes d'abattoirs (OABA) contra Ministre de l'Agriculture et de l'Alimentation y otros, resolvió una cuestión prejudicial planteada por el Tribunal de Apelación de lo ContenciosoAdministrativo de Versalles (Francia), y que tuvo como objeto la interpretación del artículo 13 del Tratado de Funcionamiento de la Unión Europea, el Reglamento (CE) n. ${ }^{\circ} 834 / 2007$ del Consejo, sobre producción y etiquetado de los productos ecológicos, el Reglamento (CE) n. ${ }^{\circ}$ 889/2008 de la Comisión, por el que se establecen disposiciones de aplicación del Reglamento n. ${ }^{\circ}$ 834/2007, y el Reglamento (CE) n. ${ }^{\circ}$ 1099/2009 del Consejo, relativo a la protección de los animales en el momento de la matanza ${ }^{49}$.

El órgano jurisdiccional nacional planteó la cuestión prejudicial sobre si las normas europeas enunciadas permiten la utilización de la etiqueta $A B$, logotipo ecológico de la Unión Europea, en los productos procedentes de animales que

\footnotetext{
${ }^{49}$ Reglamento (CE) n. ${ }^{\circ}$ 834/2007 del Consejo, de 28 de junio de 2007, sobre producción y etiquetado de los productos ecológicos y por el que se deroga el Reglamento (CEE) n. ${ }^{\circ}$ 2092/91, DO, L 189, 20 de julio de 2007, p. 1; Reglamento (CE) n. ${ }^{\circ}$ 889/2008 de la Comisión, de 5 de septiembre de 2008, por el que se establecen disposiciones de aplicación del Reglamento n. ${ }^{\circ}$ 834/2007, DO, L 250, 18 de septiembre de 2008, p. 1; Reglamento (UE) n. ${ }^{\circ}$ 271/2010 de la Comisión, que modifica el Reglamento (CE) n..$^{\circ}$ 889/2008 por el que se establecen disposiciones de aplicación del Reglamento (CE) n. ${ }^{\circ}$ 834/2007 del Consejo, en lo que atañe al logotipo de producción ecológica de la Unión Europea de 24 de marzo de 2010, DO, L 84, 31 de marzo de 2010, p. 19; y Reglamento (CE) n. ${ }^{\circ}$ 1099/2009 del Consejo, de 24 de septiembre de 2009, relativo a la protección de los animales en el momento de la matanza, DO, L 303, 18 de noviembre de 2009, p. 1.
} 
han sido objeto de un sacrificio ritual sin aturdimiento previo, realizado conforme a las previsiones del Reglamento (CE) n. ${ }^{0}$ 1099/2009 50. Entre las argumentaciones recogidas en la sentencia, el Tribunal de Justicia destacó la importancia de "garantizar que los consumidores puedan tener la seguridad de que los productos con el logotipo ecológico de la Unión Europea efectivamente se han obtenido observando las normas más exigentes, entre ellas las relativas al bienestar animal" 51 . Consideraciones como ésta llevaron al Tribunal a declarar en su fallo que "el Reglamento (CE) n. ${ }^{\circ}$ 834/2007 [...], en relación con el artículo 13 TFUE, debe interpretarse en el sentido de que no autoriza la utilización del logotipo de producción ecológica de la Unión Europea, contemplado en el artículo 57, párrafo primero, del Reglamento (CE) n. ${ }^{\circ}$ 889/2008 de la Comisión $[\ldots]$, para productos procedentes de animales que hayan sido objeto de un sacrificio ritual sin aturdimiento previo, efectuado en las condiciones establecidas en el Reglamento (CE) n. ${ }^{\circ}$ 1099/2009 [...]".

\subsection{Residuos.}

En este apartado se incluyen dos sentencias relativas a la normativa europea en materia de residuos. En primer término y por orden cronológico, cabe señalar la sentencia del Tribunal de Justicia de la Unión Europea (Sala Segunda) de 28 de marzo de 2019, as. C-60/18, Tallinna Vesi As contra Keskkonnaamet, que resolvió una cuestión prejudicial planteada por el Tribunal de Apelación de Tallin (Estonia), y en la que se preguntó sobre la interpretación del artículo 6.4 de la Directiva 2008/98/CE, sobre residuos ${ }^{52}$. El litigio principal que produjo este pronunciamiento tenía como objeto la adopción por la Agencia de Medio Ambiente de Estonia de dos decisiones sobre la valorización de residuos, en las que no se aceptó el fin de la condición de residuo de lodos de depuración sometidos a tratamiento de valorización.

\footnotetext{
50 Véase párrafo 33.

51 Véase párrafo 51.

52 Directiva 2008/98/CE del Parlamento Europeo y del Consejo, de 19 de noviembre de 2008, sobre los residuos y por la que se derogan determinadas Directivas, DO, L 312, 22 de noviembre de 2008, p. 3.
} 
El artículo 6.4 de la Directiva 2008/98/CE establece que cuando no se hayan establecido criterios a escala comunitaria, "los Estados miembros podrán decidir caso por caso si un determinado residuo ha dejado de serlo teniendo en cuenta la jurisprudencia aplicable". Ante el caso planteado, el órgano jurisdiccional nacional consultó al Tribunal de Justicia sobre si este precepto debe "interpretarse en el sentido de que se opone a una normativa nacional, como la controvertida en el litigio principal, en virtud de la cual, si no se ha establecido ningún criterio a escala de la Unión sobre el fin de la condición de residuo en el caso de un determinado tipo de residuos, el fin de la condición de residuo depende de si existen criterios definidos por un acto interno de alcance general sobre ese tipo de residuos y si, en tales circunstancias, un poseedor de residuos puede exigir que la autoridad competente del Estado miembro o un órgano jurisdiccional del Estado miembro constate el fin de la condición de residuo, de conformidad con la jurisprudencia del Tribunal de Justicia" 53.

En su pronunciamiento, el Tribunal de Justicia analizó los principales elementos del caso, y señaló que "la valorización de los lodos de depuración implica determinados riesgos para el medio ambiente y para la salud humana, en particular los relacionados con la presencia de sustancias peligrosas. Pues bien, en lo que atañe a tales sustancias, habida cuenta del margen de apreciación de que disponen, [...] los Estados miembros pueden optar por no constatar el fin de la condición de residuo de un producto o de una sustancia o por no elaborar ninguna norma cuyo cumplimiento lleve a poner fin a la condición de residuo de dicho producto o sustancia"54. Teniendo en cuenta esta precisión, el Tribunal respondió a las cuestiones planteadas y en su fallo declaró que el artículo 6.4 de la Directiva 2008/98/CE "no se opone a una normativa nacional, como la controvertida en el litigio principal, en virtud de la cual, si no se ha elaborado ningún criterio a escala de la Unión Europea para determinar el fin de la condición de residuo en relación con un tipo de residuos determinado, el fin de la condición de residuo depende de si existen criterios definidos por un acto interno de alcance general relativo a ese tipo de residuos", a lo que añadió que "no permite

\footnotetext{
53 Véase párrafo 17.

54 Véase párrafo 28.
} 
a un poseedor de residuos, en circunstancias como las del litigio principal, exigir que la autoridad competente del Estado miembro o un órgano jurisdiccional del Estado miembro constate el fin de la condición de residuo".

Un segundo pronunciamiento en materia de residuos se produjo en la sentencia del Tribunal de Justicia de la Unión Europea (Sala Décima) de 28 de marzo de 2019, as. C-487/17 y C-489/17, que resolvió una cuestión prejudicial planteada por el Tribunal Supremo de Casación de Irlanda, en la que se cuestionó la interpretación del artículo 4.2 y el Anexo III de la Directiva 2008/98/CE, sobre residuos, en su versión modificada por el Reglamento (UE) n. ${ }^{\circ}$ 1357/2014 de la Comisión; y el anexo de la Decisión 2000/532/CE de la Comisión por la que se establece una lista de residuos peligrosos, en su versión modificada por la Decisión 2014/955/UE de la Comisión ${ }^{55}$. Como se señala en la sentencia, "las peticiones de decisión prejudicial fueron presentadas en el marco de tres litigios relativos a unos procedimientos penales incoados contra una treintena de inculpados, acusados de delitos relacionados con el tratamiento de residuos peligrosos ${ }^{56}$.

El Tribunal examinó de forma conjunta tres de las cuatro preguntas presentadas por el órgano jurisdiccional nacional, que se concretaron en si las normas europeas referidas debían interpretarse "en el sentido de que el poseedor de un residuo que puede clasificarse en unos códigos espejo, pero cuya composición no se conoce de antemano, está obligado, con vistas a esa clasificación, a determinar la composición del residuo de que se trate y a investigar si este contiene una o varias sustancias peligrosas para determinar si presenta características de peligrosidad. En caso de respuesta afirmativa, pregunta

\footnotetext{
${ }^{55}$ Reglamento (UE) n. ${ }^{\circ}$ 1357/2014 de la Comisión, de 18 de diciembre de 2014, DO, L 365, 19 de diciembre de 2014, p. 89; Decisión 2000/532/CE de la Comisión, de 3 de mayo de 2000, que sustituye a la Decisión 94/3/CE por la que se establece una lista de residuos de conformidad con la letra a) del artículo 1 de la Directiva 75/442/CEE del Consejo relativa a los residuos y a la Decisión 94/904/CE del Consejo por la que se establece una lista de residuos peligrosos en virtud del apartado 4 del artículo 1 de la Directiva 91/689/CEE del Consejo relativa a los residuos peligrosos, DO, L 226, 6 de septiembre de 2000, p. 3; y Decisión 2014/955/UE de la Comisión, de 18 de diciembre de 2014, DO, L 370, 30 de diciembre de 2014, p. 44.

${ }^{56}$ Véase párrafo 13.
} 
igualmente con qué grado de determinación y según qué métodos está obligado a hacerlo" 57 .

Como respuesta a estas preguntas, el Tribunal declaró en su fallo que el Anexo III de la Directiva 2008/98/CE, y el anexo de la Decisión 2000/532/CE de la Comisión, "deben interpretarse en el sentido de que el poseedor de un residuo que puede clasificarse tanto con códigos correspondientes a residuos peligrosos como con códigos correspondientes a residuos no peligrosos, pero cuya composición no se conoce de antemano, está obligado, con vistas a esa clasificación, a determinar dicha composición y a investigar las sustancias peligrosas de las que cabe razonablemente suponer que están presentes en él para determinar si ese residuo presenta características de peligrosidad y de que, a tal efecto, el poseedor del residuo puede utilizar métodos de toma de muestras, análisis químicos y ensayos de los establecidos en el Reglamento (CE) n. ${ }^{\circ}$ 440/2008 de la Comisión, de 30 de mayo de 2008, por el que se establecen métodos de ensayo de acuerdo con el Reglamento (CE) n. ${ }^{\circ}$ 1907/2006 del Parlamento Europeo y del Consejo relativo al registro, la evaluación, la autorización y la restricción de las sustancias y preparados químicos (REACH), o cualquier otro método de toma de muestras, análisis químico y ensayo reconocidos a nivel internacional".

El órgano jurisdiccional nacional incluyó una cuarta pregunta referida al principio de cautela, en la que se pedía al Tribunal que se pronunciara sobre si en caso de duda sobre la clasificación de un residuo como peligroso, debiera efectuarse por aplicación de este principio ${ }^{58}$. Para responder a esta pregunta, el Tribunal recordó el alcance, y límites del principio de cautela para declarar en su fallo que "debe interpretarse en el sentido de que cuando, tras una evaluación de los riesgos lo más completa posible habida cuenta de las circunstancias particulares del caso concreto, el poseedor de un residuo que puede clasificarse tanto con códigos correspondientes a residuos peligrosos como con códigos correspondientes a residuos no peligrosos se encuentre en la imposibilidad práctica de determinar la presencia de sustancias peligrosas o de evaluar las

\footnotetext{
57 Véase párrafo 36.

58 Véase párrafo 55.
} 
características de peligrosidad que presente el citado residuo, este debe clasificarse como residuo peligroso". 